\title{
Notch signaling and EMT in non-small cell lung cancer: biological significance and therapeutic application
}

\author{
Xun Yuan, Hua Wu, Na Han, Hanxiao Xu, Qian Chu, Shiying Yu, Yuan Chen and Kongming Wu*
}

\begin{abstract}
Through epithelial-mesenchymal transition (EMT), cancer cells acquire enhanced ability of migration and invasion, stem cell like characteristics and therapeutic resistance. Notch signaling regulates cell-cell connection, cell polarity and motility during organ development. Recent studies demonstrate that Notch signaling plays an important role in lung cancer initiation and cross-talks with several transcriptional factors to enhance EMT, contributing to the progression of non-small cell lung cancer (NSCLC). Correspondingly, blocking of Notch signaling inhibits NSCLC migration and tumor growth by reversing EMT. Clinical trials have showed promising effect in some cancer patients received treatment with Notch1 inhibitor. This review attempts to provide an overview of the Notch signal in NSCLC: its biological significance and therapeutic application.
\end{abstract}

Keywords: Notch signaling, Epithelial-mesenchymal transition (EMT), Cancer stem cells (CSCs), Non-small-cell lung cancer (NSCLC), Gamma secretase inhibitor

\section{Current status of NSCLC}

Lung cancer is a serious public health problem that affects the lives of millions and is the most common cause of cancer-related mortality [1]. Moreover, according to WHO projections, the global burden of lung cancer is expected to rise due to industrial and environmental pollution and many other factors. In 2010, a report from National Central Cancer Registry of China demonstrated that the lung cancer incidence and mortality increased to $46.08 / 100,000$ and $37.00 / 100,000$, respectively [2]. Non-small cell lung cancer (NSCLC) accounts for approximately $80 \%$ of all lung cancers. NCI SEER database reported that 5-year survival was $58.2 \%$ for NSCLC patients diagnosed at localized stage (18\%) of all stages including localized, regional and distant from 2004-2010, whereas it was only 4.5\% when diagnosed at distant stage (55\%) [3]. Although many advances achieved in cancer biology as well as in diagnosis and treatment, progress in lung cancer therapy has been slow, leading to about $5 \%$ improvement in 5 -year survival rates for the last 20 years [4].

\footnotetext{
* Correspondence: kmwu@tjh.tjmu.edu.cn

Department of Oncology, Tongji Hospital of Tongji Medical College,

Huazhong University of Science and Technology, Building 303, 1095 Jie Fang Avenue, Wuhan 430030, P.R. China
}

(c) 2014 Yuan et al.; licensee BioMed Central Ltd. This is an Open Access article distributed under the terms of the Creative Commons Attribution License (http://creativecommons.org/licenses/by/4.0), which permits unrestricted use, distribution, and reproduction in any medium, provided the original work is properly credited. The Creative Commons Public Domain Dedication waiver (http://creativecommons.org/publicdomain/zero/1.0/) applies to the data made available in this article unless otherwise stated.

Most important advances include the discovery of oncogenic driver genes and therapies specific for these genes or pathways. The common driver genes identified so far in NSCLC included the mutant activations of KRAS, EGFR, Met and BRAF [5]. In comparison with standard chemotherapy, new target therapies show a significant improved progression-free survival (PFS) and relatively less toxicity [4]. However, the median PFS of NSCLC patients with EGFR mutation was only 9.5 months on treatment with tyrosine kinase inhibitors (TKIs) [6]; The median PFS for patients with locally advanced ALK-positive lung cancer was only 7.7 months with crizotinib treatment [7]. Moreover, the overall survivals are not significantly improved for patients received target therapy as compared with chemotherapy [6-8]. It is obviously that overcoming refractory to target drugs can prolong treatment response. In this respect, experimental study proved that inhibition of hedhehog signaling abrogated resistance of NSCLC to TKI [9].

Novel inhibitors targeting multiple kinase sites are extensively developed, some have entered clinical trial. For example, a novel kinase inhibitor targeting both EGFR and HER2 has been evaluated in lung and breast cancer in phase I study and is expected to bring improved response 
[10]. Meanwhile, combination of target drugs with traditional chemotherapeutics had also been deployed, such as the conjunction of MEK inhibitors with anti-cancer drug docetaxel in previously treated patients with advanced lung cancer. Combined therapy revealed better response rate and prolonged PFS than chemotherapy alone in a phase II randomized trial [11].

In translational research, scientists performed comprehensive molecular studies to search for new genes in lung cancer. Whole-genome and transcriptome sequencing of tumor and adjacent normal tissue samples from NSCLC had identified novel alterations in genes involved in chromatin modification and DNA repair pathways, novel metabolic enzymes, as well as aberration of cell fate determination factor DACH1 [12]. Further experimental study confirmed tumor suppresser function of DACH1 in lung and other cancers $[13,14]$. Most recent study to molecularly profile 230 resected adenocarcinomas revealed recurrent aberrations in multiple known pathways and previously unknown mutations of RIT1 and NF1 as new driver genes [15], suggesting the complexity of NSCLC. Recently, novel genes or pathways involved in tumor initiation and progression have been identified. For instance, metastasis associated lung adenocarcinoma transcript 1 (MALAT1), a long non-coding RNA (lncRNA), has been proven to function as a key regulator of brain metastasis in NSCLC. By inhibiting epithelial-mesenchymal transition (EMT), silencing MALAT1 reduced lung cancer cell invasion and metastasis. Clinically, protein abundance of MALAT1 correlated tightly with the poor prognosis of patients [16]. Although many risk factors have been connected tightly with the initiation and progression of NSCLC, currently there is no satisfactory strategy that can effectively prevent the cancer progression. Since extensive invasion and remote metastases severely prevent the option of surgical intervention and are key causes for lung cancer death, how to block those processes is always a critical topic for basic research and clinic management. Therapeutic refractory lung cancer cells frequently reveal EMT phenotype and signaling to block EMT has been shown to enhance chemotherapy sensitivity $[17,18]$. Taken together, EMT, metastases and drug resistance are intertwined in NSCLC, which lead to aggravation and poor prognosis. Therefore, more attention should be placed on seeking potential pathways and new targets to improve treatment outcome of NSCLC.

\section{The role of EMT and CSCs in Metastasis of NSCLC}

EMT is a highly coordinated process, in which epithelial cells lose polarity together with cell-cell adhesion and acquire properties of mesenchymal cells. Key transcription factors driving EMT include the Snail homologues (Snail1, Snail2/Slug and Snail3), twist, zinc finger E-boxbinding homeobox 1 (ZEB1) and ZEB2, and TCF3/E47/
E12 [19,20]. Multiple signaling pathways, such as transforming growth factor $\beta$ (TGF- $\beta$ ), bone morphogenetic protein (BMP), Wnt- $\beta$-catenin, Notch, Hedgehog, and receptor tyrosine kinases participate in this transition [21] (Figure 1). In vitro studies have proved that TGF- $\beta$, integrin and JAK/STAT3 signals caused EMT in lung adenocarcinoma cells [22-24]. The ability to invade and disseminate of epithelial cells strongly relies on a dramatic remodeling of the cytoskeleton, leading to the invasive properties in promoting tumor metastasis accompanied with the acquisition of mesenchymal phenotype [25]. E-cadherin, the cadherin superfamily of $\mathrm{Ca}^{2+}$-dependent adhesion molecules, plays a key role in the regulation of cell-cell interactions [26]. Epigenetically silenced E-cadherin expression was observed in advanced NSCLC and restoration of Ecadherin expression strongly decreased the invasion/ migration of tumor cells [27]. In contrast, the upregulation of $\mathrm{N}$-cadherin expression is linked to the metastasis of NSCLC, whereas inhibition of N-cadherin was demonstrated to reduce the proliferation and invasion of NSCLC [28]. Additionally, the cell-cell communication determines cell signaling, cell-cell interaction and cell polarity. For example, the intercellular cell-adhesion molecule-1 (ICAM-1), a transmembrane molecule and a distinguished member of the immunoglobulin superfamily of proteins, was involved in tumor invasion and EMT, and was also correlated with tumor differentiation grade and survival of NSCLC patient [29].

Via inducing translation suppression and mRNA degradation, micro-RNAs serve as key administrators of posttranscriptional regulation and also participate in EMT [30]. More studies have proved that post-transcriptional regulatory network, such as miR-200 family, miR-101, miR-506, and several lncRNAs regulated EMT [31]. Hypoxia is one of the fundamental biological phenomena that is intricately associated with the development and aggressiveness of a variety of solid tumors. Multiple signaling pathways such as NF-kB, PI3K/Akt/mTOR, Notch, Wnt/ $\beta$-catenin, and Hedgehog as well as hypoxia-induced microRNAs (miRNAs) have been recognized as important regulators of EMT in hypoxia environment, promoting tumor progression [32,33].

The cancer stem cell (CSC) theory proposed that the malignant phenotype was sustained by a subset of cells characterized by the capacity for self-renewal and differentiation. It is believed that CSCs are responsible for propagating growth, distant metastasis and recurrence [34]. Those cells also enriched the expression of pluripotency genes and epithelial-mesenchymal transition transcription factors, along with reduced intercellular adhesion protein expression. However, the precise origin of lung CSCs is still not clear [35]. Potential markers for identifying lung cancer stem cells include CD133, CD44, ALDH, CD166 and BMI. Analyses in multiple established and patient-derived 


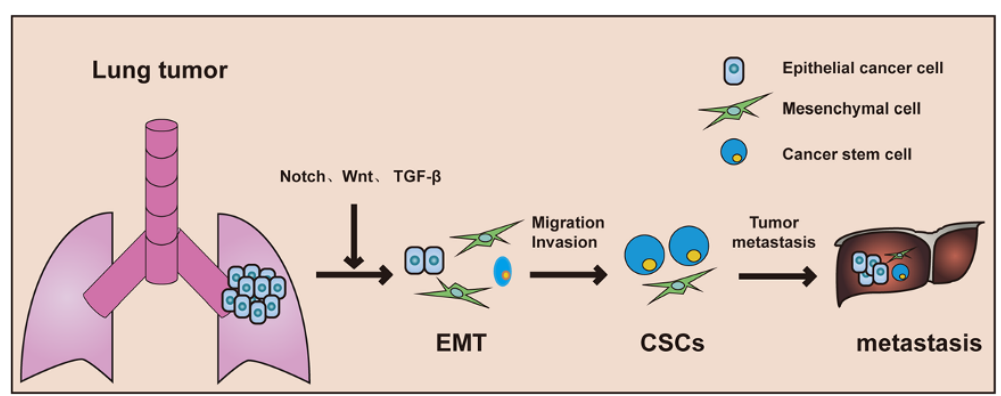

Figure 1 The signaling pathways in lung cancer. Oncogene activation or loss of tumor suppressor initiates lung tumor formation. The Notch, Wnt and TGF- $\beta$ signaling pathway are involved in the induction of EMT, CSCs and metastasis of NSCLC.

lung cancer cells well demonstrated that subpopulation of ALDH(hi)CD44(hi) cells showed self-renewal, clonogenicity, highly tumorigenic, high invasion capacities, and resistance to chemotherapy [36]. Embryonic stem cell pathways such as Notch, Hedgehog and WNT were found active in lung cancers stem cells. Majority of human lung adenocarcinoma samples demonstrated expression of SPC, clara cell secretory protein (CCSP) and OCT4, characteristics of bronchioalveolar stem cell(BASC) [37,38]. Experiment demonstrated that in mouse and human airway basal stem cells (ABSCs), activation of the Notch pathway was required for ROS to stimulate ABSC self-renewal [39].

Altogether, EMT is frequently associated with stemness property and therapeutic resistance, which contributes to aggressive tumor growth, invasion and metastasis, and is also recognized as the cause of tumor recurrence. In one hand, the expressions of embryo stem cell related genes are enriched on cells under EMT [38]. At the other hand, knockdown of stem cell factor, Oct4/Nanog, suppressed the expression of EMT gene Slug and reversed the EMT process, followed by reduced tumorigenic and metastatic ability. Importantly, survival time for mice bearing transplanted tumor double knockdown of Oct4/Nanog was also greatly improved [40]. Moreover, the immunohistochemical stain demonstrated expressions of Oct4, Nanog and Slug were associated in high-grade human lung adnecarcinoma tissues and the patients with triple positivity of Oct4/Nanog/Slug indicated a worse prognosis [40].

\section{The Notch signaling pathway in NSCLC}

The Notch signaling is activated by ligand binding to receptor to initiate an intercellular communication system [41]. There are five ligands, namely Delta-like 1, Delta-like 3, Delta-like 4, Jagged-1 and Jagged-2, and four receptor members (Notch $1 \sim 4$ ). Ligand binding induces conformational change in Notch, leading to the exposure of S2 site for sequentially cleavage by a member of the A Disintegrin And Metalloproteinase family of proteases and the gamma secretase complex to liberates the Notch Intracellular Domain (ICD), then ICD translocates to the nucleus [42]. In the nucleus, ICD binds with the transcription factor
CBF-1/suppressor of hairless/Lag1 (CSL) and modulates gene expression (Figure 2). Without ICD, CBF-1 protein binds to the consensus DNA sequence in association with SMART complex, acting as a transcriptional repressor. Interaction of CBF-1 with ICD displaces the corepressor SMART/HDACs complex, allowing for the transcriptional activation of target genes, primarily involving in two families of helix-loop-helix transcription factors: Hes (Hairy enhance of split) and Hey (Hairy/enhancer of spit related with YRPW motif) targeting genes. Other known target genes include cyclinD1, c-myc, p21, p27, the nuclear factor-kappa B (NF-kB), Survivin, Slug and Nanog [43].

Overwhelming evidence has proven that Notch signaling is crucial for the development and homeostasis of most tissues. Notch signaling has been known to participate in cell proliferation, differentiation and apoptosis. Earlier studies discovered that deregulated Notch signaling leads to various diseases, such as T cell leukemia and breast cancer $[44,45]$. Notch1 mediates hypoxia-induced proliferation, invasion and chemoresistance [46]. Hypoxia also induced CD133 expression, which has been used as a stem cell biomarker of stem-like cells [47]. Subsequent study demonstrated that Notch signaling drived stemness and tumorigenicity of esophageal adenocarcinoma [48]. However, the effects of Notch signaling pathway on controlling cell fates are cell- and tissue-type dependent. Notch activation in bladder cancer cells suppresses proliferation by reducing the phosphorylation of ERK1 and ERK2 (ERK1/2). In support of this, genetic inactivation of Notch signaling in mouse models leads to Erk1/2 phosphorylation, resulting in tumorigenesis in the urinary tract [49].

The involvement of Notch on lung cancer was experimentally proved in transgenic mouse model by the alveolar epithelium specific expression of activated Notch [50]. The mice developed alveolar hyperplasias as early as 7 days' induction of Notch and the lesions progressed to pulmonary adenomas after 8 months' induction. Molecular analyses revealed that Notch1 activation leads to dysregulated expansion of type II lung epithelial cells. When crossed with mice conditionally overexpressing MYC in the alveolar epithelium, mice developed adenocarcinomas. 


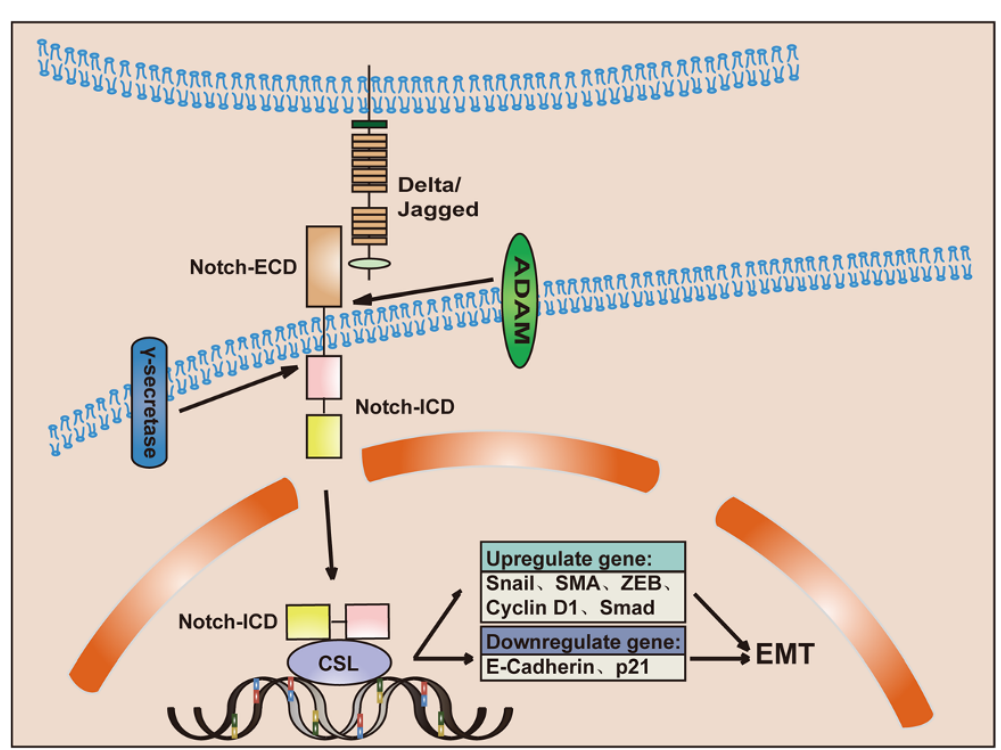

Figure 2 Schematic representation of Notch signaling related to EMT. Upon ligand binding, Notch undergoes two proteolytic cleavages by ADAM and $\gamma$-secretase complex, leading to the release of Notch-ICD and its translocating to the nucleus. In the nucleus Notch-ICD interacts with CSL and activates numerous downstream target genes: upregulation of snail, slug, zeb1, cyclinD1 and Smad; downregultion of E-cadherin, p21, etc. to induce EMT. (Notch-ECD, the extracellular domain of Notch; Notch-ICD, the intracellular domain of Notch; ADAM, a disintegrin and metalloproteinase; CSL, CBF-1/suppressor of hairless/Lag1).

Those pathological processes mimic progression of human adenocarcinoma. Using an autochthonous model of lung adenocarcinoma with concomitant expression of oncogenic Kras and deletion of Notch1, Dr. Kissil's group found that Notch1 function was required for tumor initiation via suppression of p53-mediated apoptosis through the regulation of p53 stability [51]. Molecular analyses defined subpopulation of CD24 (+) ITGB4 (+) Notch (hi) cells were capable of propagating tumor growth in both clonogenic and an orthotopic serial transplantation assays. While all four Notch receptors represented tumorpropagating cells, Notch3 plays a nonredundant role in Kras models and in human NSCLC [52]. Interestingly, in K-Ras mouse model, inhibition of Notch strongly inhibits adenocarcinoma formation but promotes squamous hyperplasia in the alveoli. In contrast, activation of Notch leads to widespread Sox2 (+), Sox9 (+), and CC10 (+) papillary adenocarcinomas throughout the bronchioles [53]. Those researches supported a strong and direct role of Notch signaling in NSCLC. Other studies had shown that under hypoxic conditions, Notch1 stimulated NSCLC tumor growth through direct upregulation of IGF1-R [54] and survivin [55], both of which enhanced cell proliferation and survival.

In clinic study, activation of Notch signaling by either Notch1 upregulation or Numb downregulation was observed in 30\% of primary human NSCLCs [56]. Notch3 also appears to be a key player in NSCLC, with overexpressed in $40 \%$ of NSCLC tumors [57]. In experimental study, either dominant-negative Notch3 receptor [58] or MRK-003, a gamma-secretase inhibitor [59], antagonized Notch3 signaling, attenuated cell growth, and induced apoptosis of lung cancer cell lines. In depth molecular analyses demonstrated crosstalk between the Notch3 and the EGFR pathway resulted in the inhibition of apoptosis through expression of anti-apoptotic protein BIM [60]. For precise target therapy, the specific region within the Notch3 extracellular domain with EGF receptor-like repeats was identified and that might be responsible for the distinct effects of Notch3 versus those of Notch1. Functional study showed peptides from these regions induced apoptosis in NSCLC [61].

Clinically oriented studies have highlighted that Notch signaling impacts survival in lung cancer patients. A recent study by Donnem et al. assessed the prognostic impact of Notch ligands and receptors in NSCLC and found that high Notch1 expression was statistically significantly associated with poor outcomes in lung adenocarcinoma [62]. Elevated levels of Notch-1, 3 and their ligand Jagged 1-4 expressions were found to be associated with tumor progression and predicted poor prognosis in NSCLC, suggesting a promising biomarker for NSCLC $[62,63]$. Delta-like ligand 4 and Notch-1 are independent prognostic factors in NSCLC, but show diverse impacts in squamous cell carcinoma and adenocarcinoma. In addition, Jagged-1 was found to be highly expressed in metastatic NSCLC compared to localized NSCLC [63]. The coexpression of Notch-1/VEGF-A has a major impact 
on survival, suggesting Notch regulated angiogenesis is involved in the metastasis and determines the prognosis of NSCLC.

\section{Mechanism of Notch signaling in regulating EMT}

Notch signaling pathway participates in an elaborate gene program and protein network for the establishment of motile and invasive mesenchymal phenotypes from polarized epithelial properties, such as cell-cell connections and cell polarity [64]. It was first revealed that Notch activity induced EMT was required for cardiac valve and cushion formation during heart development, involving downregulation of epithelial markers (E-cadherin) and upregulation of mesenchymal markers (snail) $[65,66]$. Meanwhile, inactivation of Notch signaling by a $\gamma$-secretase inhibitor could reverse the EMT process [67]. Interestingly, over-expression of Jagged1 could trigger repression of Ecadherin in human kidney epithelial cells, suggesting Jagged-1 is a necessary element of Notch signaling for promoting EMT [68]. In EMT processes, Notch crosstalks with several transcription and growth factors relevant to EMT, including Snail, Slug, TGF- $\beta$, FGF, and PDGF [21,69]. Key targets in Notch signaling are discussed below.

\section{Notch, Snail and E-cadeherin}

Crystallization of Snail illustrates that it contains a conserved carboxy-terminal region with 4-to 6- $\mathrm{C}_{2} \mathrm{H}_{2}$-zinc fingers. By attaching through finger structures to E-box motifs (5'-CANNTG-3') in target promoters, such as the E-cadherin gene $(C D H 1)$ promoter, Snail1 and Snail2 (Slug) act as transcriptional repressors [70]. The reduction of E-cadherin expression reduces the cell-cell junction and leads to destabilization of the epithelial structure, which is an initial step in EMT. Experiments proved that over-expression of Notch-ICD alone could increase snail expression and resulted in the loss of E-cadherin. On the contrary, inactivation of Notch attenuated the downregulation of E-cadherin expression and decreased Snail expression, suggesting a direct role for Notch signaling via Snail in the induction of EMT [71]. By recruitment of hypoxia-inducible factors, HIF- $1 \alpha$ and HIF- $2 \alpha$, Notch signaling pathway could also increase Snail expression to promote EMT through a sophisticated framework [72]. Interestingly, the inhibition of COX-2 could reverse the ability of Notch 1 to induce EMT, suggesting that Notch is dependent on COX2 to mediate pro-metastasis via Snail/ E-cadherin in EMT [73]. Recent report from Dr. Pine's group indicates that Notch1 could regulate Sox 9 expression through directly interaction with its promoter binding site to induce cell invasion and repress E-cadherin [74]. It has also been demonstrated that Slug serves as an activator in NSCLC cell lines during the induction of EMT. Furthermore, inhibition of Notch signaling led to partial reversal of EMT by decreased expressions of Snail, Slug, ZEB1, vimentin, and nuclear factor-kappaB, showing slug was essential for Notch-mediated EMT [75]. These findings linked Notch pathway and Snail/Slug tightly, making them attractive targets for new therapeutics.

\section{Notch and ZEB}

ZEB family (ZEB1 and ZEB2), another group of transcription factor, contributes to tumorigenicity as well as EMT in NSCLC [76,77]. ZEB1 suppresses the expression of cell polarity factors, in particular of Lgl2, which is critical for the epithelial phenotype and that its loss is involved in metastasis [78]. Correspondingly, inhibition of ZEB1 reverses EMT and chemo-resistance in docetaxelrefract human lung adenocarcinoma cell line [79]. Immunohistochemical analyses of clinical sample revealed that ZEB1 and twist are more commonly expressed in metastatic than primary lung tumors and show inverse associations with claudins [80]. Subpopulation of metastasisprone mouse lung adenocarcinoma cells expresses high level of Notch and Notch ligands, but decreased miR-200. Reduction in Notch signaling resulted in reduced proliferation, increased apoptotic susceptibility, and decreased tumorsphere formation [81]. It is concluded that interaction of Notch-miR-200-ZEB1 loop governed EMT and metastatic capacity. This novel Notch/miR-200-dependent pathway, which mediates lung adenocarcinoma metastasis in mice, may provide new target for the treatment of human epithelial tumors.

\section{Notch and TGF- $\beta$}

The transforming growth factor beta (TGF- $\beta$ ), a ubiquitous cytokine with profound growth inhibitory effects on epithelial and other tissues, orchestrates an intricate signaling network that is crucial to determine cell fate, differentiation, proliferation and motile, leading to not only tumour suppression but also EMT [82]. The TGF- $\beta$ superfamily consists of the TGF- $\beta$ family (TGF- $\beta 1$, TGF- $\beta 2$ and TGF- $\beta 3$ ), NODAL, activins, and bone morphogenetic proteins (BMPs). Initiated by ligand-receptor binding, TGF- $\beta$ mediates the interaction of SMAD to the promoters of Snail, contributing to the development of EMT in NSCLC $[83,84]$. TGF- $\beta$ induced EMT could be blocked by knock down of Hey-1 or jagged-1 and by pharmacological inactivation of Notch, indicating the key role of Notch signaling in TGF-beta-induced EMT [85]. Meanwhile, inhibition of Notch signaling could significantly inhibit TGF- $\beta$-induced expression of SMA, suggesting Notch induced EMT through a TGF- $\beta$-Smad3 pathway that activates SMA gene transcription [86]. However, in cultured limbal progenitor cells, Notch prevents TGF- $\beta$-assisted EMT through the induction of Smad7 [87]. While in breast cancer, Notch pathway inhibits TGF- $\beta$ signaling through HEYL-mediated crosstalk, promoting initiation of breast cancer [88]. 
Collectively, these studies indicate that the cross talk between Notch signaling and TGF- $\beta$ play a profound role in EMT.

\section{Notch and Cyclin D1}

Hyper-activation of cyclins, especially the G1/S administrator cyclin D1 may favor tumor development by inducing unscheduled cell division in progenitor cells [89]. The abundance of cyclin D1 has a significant relationship with neoplastic progression of NSCLC [90,91]. In epithelial ovary cancer cells, stem-like CD24- cells or spheroids highly expressed cyclin D1, Bmi-1, and vimentin with reduced expression of E-cadherin, while non stem-like CD24+ or parental cells showed the opposite expression. Furthermore, cyclin D1-targeted small interfering RNA resulted in decreased vimentin expression in spheroids, accompanying with reduced cell viability and migration [92]. In cervical squamous carcinoma, most invasive tumour cells expressed cyclin D1 and showed a reduction in Ecadherin and beta-catenin staining [93]. Epidermoid A431 cells expressing SIP1 along with exogenous cyclin D1 were highly invasive, indicating that SIP1-regulated invasion is independent of attenuation of G1/S progression [94]. Conversely, knock down Notch-3 reduced cyclin D1 with reduced proliferation and enhanced apoptosis [95]. Given the importance of Notch and cyclin D1 in tumorigenesis, it is not surprising that Notch pathway would participate in regulation of cyclin D1-mediated EMT. Activation of Notch signaling during neural induction in the ES cells led to significantly enhanced cell proliferation, accompanied by Notch-mediated activation of cyclin D1 expression. A reduction of cyclin-D1-expressing cells was observed in the developing CNS of Notch signaling-deficient mouse embryos. Moreover, expression of a dominant negative form of cyclin D1 in the ES cells abrogated the Notch-induced proliferative ability, and, conversely, a constitutively active form of cyclin D1 mimicked the effect of Notch on cell proliferation [96]. Gifitinib-acquired resistant lung cancer cells displayed EMT phenotype. Molecular analyses confirmed that activation of Notch-1 and its target genes, which induced expression of mesenchymal marker vimentin, snail and hes-1, and decreased epithelial marker E-cadherin. The elevated expression of Notch-1 could directly suppress p21 Waf1/Cipl accompanied with the increasing of cyclin D1, giving rise to the EMT phenotype. Meanwhile, knockdown of Notch-1 decreased cyclinD1 expression and reversed EMT. These findings suggest that the aggressive behavior caused by cyclinD1 might be driven by the mis-expression of Notch pathway in NSCLC, which finally down regulates p21 Waf1/Cipl and promotes the EMT phenotype [71].

\section{Targeting Notch signaling in NSCLC}

In vivo evidence that Notch inhibitor is a potential therapeutic agent came from Kras(G12V)-driven NSCLCs mice model. Pharmacologic treatment of mice carrying autochthonous NSCLCs with a $\gamma$-secretase inhibitor (GSI) blocked cancer growth. Correspondingly, molecular analysis of treated cancer tissues demonstrated reduced HES1 levels and phosphorylated ERK [97]. Currently, several classes of investigational Notch inhibitors have been developed. These include monoclonal antibodies against Notch receptors or ligands, decoys to soluble forms of the extracellular domain of Notch receptor or Notch ligands, blocking peptides, and gamma-secretase inhibitors (GSIs) or natural compounds [98].

At present, GSIs are the most extensively explored. RO4929097, a small-molecule inhibitor of GSI with high oral bioavailability and is a potent and selective inhibitor of gamma-secretase, has been tested in phase I study in refractory metastatic or locally advanced solid tumors [99], and phase II studies for metastatic melanoma [100], metastatic colorectal cancer [101] and metastatic pancreatic adenocarcinoma [102]. Another GSIs, PF-03084014, was also evaluated on phase I in advanced solid tumor [103]. In preclinical study, MRK-003 was evaluated in triple negative breast cancer cells by MRK-003 alone and in combination with paclitaxel. Immunohistochemical staining for activated NOTCH1 and HES4 expression could be molecular biomarkers, identifying solid tumors that are likely to respond to GSI-based therapies [104]. Preclinical study of MRK-003 in pancreatic cancer [105] and in multiple myeloma and non-Hodgkin's lymphoma exhibited promising activity [106]. Treatment with GSIs MK-0752 in breast cancer cell lines reduced stem cell subpopulation in vitro and in human tissues from clinical trial [107]. Clinical benefit of MK-0752 in adult patients with advanced solid tumors was observed with well tolerated toxicity in Phase I study, therefore promoting to combinational trials [108].

Inhibitors of Notch signaling can be used not only as direct anti-cancer agents but also as a sensitizer to current therapy. Platinum-based chemotherapy is the first-line treatment for NSCLC, but recurrence occurs in most patients. Experimental study found that treatment of NSCLC cell line H460 and H661 enriched CD133 (+) cells and upregulated ABCG2 and ABCB1 expression, which conferred the cross-resistance to doxorubicin and paclitaxel. Detailed molecular analysis found that the enrichment of CD133 (+) cells by cisplatin depended on Notch signaling. Moreover, pretreatment with the $\gamma$-secretase inhibitor or Notch1 short hairpin RNAs (shRNA) remarkably increased the sensitivity to doxorubicin and paclitaxel. Importantly, similar phenomena were observed both in engrafted tumors derived from transplanted animal model and the relapsed tumors of patients who had received cisplatin treatment [109]. Gamma-secretase inhibitor DAPT alone slightly inhibited the proliferation and exhibited little effect on the cell cycle, but enhanced the inhibitory 
effects of Cisplatin in a combinational study with GSI. Interestingly, this effect was especially significant in CD133 (+) cells, suggesting that Notch pathway blockade may be a useful CSC-targeted therapy in lung cancer [110]. In complementary, Dr. Carbone's group found that treatment of EGFR-mutated lung cancer cell lines with erlotinib enriched the $\mathrm{ALDH}^{+}$stem-like cells with stem-like cell potential through EGFR-dependent activation of Notch3. Moreover, $\gamma$ secretase inhibitor could reverse this phenotype. At molecular level, physical association between the Notch3 and EGFR receptors leads to tyrosine phosphorylation of Notch3. This study could explain the unflavored survival observed in some studies of erlotinib treatment at early-stage disease, and imply that specific dual targeting might overcome adverse effect of TKIs [111].

$\gamma$-Secretase inhibitor administration after radiation had the greatest growth inhibition of lung cancer in vitro and in vivo. Mechanically, enhanced apoptosis of lung cancer cell lines in combination group were through regulation of MAPK and Bcl- 2 family proteins. Furthermore, radiation-induced activation of Notch was blocked by GSI administration, suggesting that treatment with GSI could prevent Notch-induced radiation resistance [112]. Together, above studies provided compelling evidence for exploiting Notch inhibitors in clinic trial. In most cases, the application of GSI is limited because of gut toxicity and goblet cell hyperplasia. Therefore, the best dose and schedule need to be optimized.

Other receptor-specific approaches like siRNA directed against Notch might be useful in reducing the tumorigenicity and invasive of NSCLC. For instance, nanoparticle (NP) technology has been applied to deliver specific siRNA to knockdown Notch1 to arrest tumor growth and reverse EMT by the up-regulation of miR-200a and downregulation of the transcription factors ZEB1, ZEB2, Snail and Slug [113]. Furthermore, monoclonal antibody against Notch can also reduce the invasion of NSCLC $[114,115]$. The complex of $\gamma$-secretase is a transmembrane protease that catalyses the cleavage of a set of membrane proteins and is comprised of four subunits encoded by four genes, including PSEN1, PSENEN, NCSTN and APH1. Targeting NCSTN using specific mAbs may represent a novel mode of treatment for invasive triple-negative breast cancer, for which there are few targeted therapeutic options. It is suggested that measuring NCSTN in patient samples may serve as a molecular marker for anti-NCSTN therapy in the clinic [116].

$>$ Some natural agents such as curcumin, 3,3'-diindolylmethane (DIM), resveratrol, and epigallocatechin-3gallate (EGCG) have been reported to be effective on targeting Notch signaling, suggesting they can also be promising alternative strategies for NSCLC chemotherapy $[117,118]$.

\section{Conclusion}

As a well known driving force of cell invasion, migration and metastasis, EMT has been shown to induce resistance of cancer cells to conventional chemotherapy and radiotherapy. Notch signaling not only activates cell proliferation, antagonize apoptosis but also cross-talks with several transcriptional factors to promote EMT, leading to enhanced motility in vitro and invasion and metastasis in vivo. Theoretically, combination of chemotherapy or radiotherapy with Notch inhibitors might acquire synergistic effect and improve chemotherapy response. Although promising results have been noticed in some patients with Notch inhibitors in clinical trials, stratification biomarkers to identify patients who are most likely benefit from GSIs treatment are required for a successful development of this class of drugs.

\section{Competing interests}

The authors declare that they have no competing interests.

\section{Authors' contributions}

$X Y, H W$ and $\mathrm{NH}$ searched literatures and prepared the manuscript. QC, SY, YC and KW designed the study, reviewed the literatures and wrote the manuscript. All authors approved the final manuscript.

\section{Acknowledgement}

This work was supported from National Science Foundation of China (Grant No. 81261120395, 81172422, 81072169 and 81301929) and the Natural Science Foundation of Hubei Province (No. 2014CFB218).

Received: 6 October 2014 Accepted: 12 November 2014

Published online: 05 December 2014

\section{References}

1. Ferlay J, Shin HR, Bray F, Forman D, Mathers C, Parkin DM: Estimates of worldwide burden of cancer in 2008: GLOBOCAN 2008. Int J Cancer 2010, 127:2893-2917.

2. Chen W, Zheng R, Zhang S, Zhao P, Li G, Wu L, He J: The incidences and mortalities of major cancers in China, 2009. Chin J Cancer 2013, 32:106-112.

3. Howlader N, Noone AM, Krapcho M, Garshell J, Miller D, Altekruse SF, Kosary CL, Yu M, Ruhl J, Tatalovich Z, Mariotto A, Lewis DR, Chen HS, Feuer EJ, Cronin KA (eds): SEER Cancer Statistics Review, 1975-2011. Bethesda, MD: National Cancer Institute. http://seer.cancer.gov/csr/ 1975_2011/, based on November 2013 SEER data submission, posted to the SEER web site, April 2014.

4. Johnson DH, Schiller JH, Bunn PA Jr: Recent clinical advances in lung cancer management. J Clin Oncol 2014, 32:973-982.

5. Rosell R, Bivona TG, Karachaliou N: Genetics and biomarkers in personalisation of lung cancer treatment. Lancet 2013, 382:720-731.

6. Fukuoka M, Wu YL, Thongprasert S, Sunpaweravong P, Leong SS, Sriuranpong V, Chao TY, Nakagawa K, Chu DT, Saijo N, Duffield EL, Rukazenkov Y, Speake G, Jiang H, Armour AA, To KF, Yang JC, Mok TS: Biomarker analyses and final overall survival results from a phase III, randomized, open-label, first-line study of gefitinib versus carboplatin/ paclitaxel in clinically selected patients with advanced non-small-cell lung cancer in Asia (IPASS). J Clin Oncol 2011, 29:2866-2874.

7. Shaw AT, Kim DW, Nakagawa K, Seto T, Crino L, Ahn MJ, De Pas T, Besse B, Solomon BJ, Blackhall F, Wu YL, Thomas M, O'Byrne KJ, Moro-Sibilot D, Camidge DR, Mok T, Hirsh V, Riely GJ, lyer S, Tassell V, Polli A, Wilner KD, Janne PA: Crizotinib versus chemotherapy in advanced ALK-positive lung cancer. N Engl J Med 2013, 368:2385-2394.

8. Kazandjian D, Blumenthal GM, Chen HY, He K, Patel M, Justice R, Keegan P, Pazdur R: Crizotinib for the Treatment of Metastatic Non-Small Cell Lung Cancer With Anaplastic Lymphoma Kinase Rearrangements. Oncologist 2014, Epub ahead of print. 
9. Ahmad A, Maitah MY, Ginnebaugh KR, Li Y, Bao B, Gadgeel SM, Sarkar FH: Inhibition of Hedgehog signaling sensitizes NSCLC cells to standard therapies through modulation of EMT-regulating miRNAs. J Hematol Oncol 2013, 6:77.

10. Zhang J, Cao J, Li J, Zhang Y, Chen Z, Peng W, Sun S, Zhao N, Wang J, Zhong D, Zhang X, Zhang J: A phase I study of AST1306, a novel irreversible EGFR and HER2 kinase inhibitor, in patients with advanced solid tumors. J Hematol Oncol 2014, 7:22.

11. Akinleye A, Furqan M, Mukhi N, Ravella P, Liu D: MEK and the inhibitors: from bench to bedside. J Hematol Oncol 2013, 6:27.

12. Govindan R, Ding L, Griffith M, Subramanian J, Dees ND, Kanchi KL, Maher CA Fulton R, Fulton L, Wallis J, Chen K, Walker J, McDonald S, Bose R, Ornitz D, Xiong D, You M, Dooling DJ, Watson M, Mardis ER, Wilson RK: Genomic landscape of non-small cell lung cancer in smokers and never-smokers. Cell 2012, 150:1121-1134

13. Chen K, Wu K, Cai S, Zhang W, Zhou J, Wang J, Ertel A, Li Z, Rui H, Quong A, Lisanti MP, Tozeren A, Tanes C, Addya S, Gormley M, Wang C, McMahon SB, Pestell RG: Dachshund binds $p 53$ to block the growth of lung adenocarcinoma cells. Cancer Res 2013, 73:3262-3274.

14. Chu Q, Han N, Yuan X, Nie X, Wu H, Guo M, Chen Y, Yu Y, Wu K: DACH1 inhibits cyclin D1 expression, cellular proliferation and tumor growth of renal cancer cell. J Hematol Oncol 2014, 7:73.

15. CancerGenomeAtlas Research Network: Comprehensive molecular profiling of lung adenocarcinoma. Nature 2014, 511:543-550.

16. Shen $L$, Chen $L$, Wang $Y$, Jiang $X$, Xia $H$, Zhuang Z: Long noncoding RNA MALAT1 promotes brain metastasis by inducing epithelial-mesenchymal transition in lung cancer. J Neurooncol 2014, Epub ahead of print.

17. Buonato JM, Lazzara MJ: ERK1/2 blockade prevents epithelial-mesenchymal transition in lung cancer cells and promotes their sensitivity to EGFR inhibition. Cancer Res 2014, 74:309-319.

18. Wilson C, Nicholes K, Bustos D, Lin E, Song Q, Stephan JP, Kirkpatrick DS, Settleman J: Overcoming EMT-associated resistance to anti-cancer drugs via Src/FAK pathway inhibition. Oncotarget 2014, 5:7328-7341.

19. Ishikawa T, Shimizu T, Ueki A, Yamaguchi Sl, Onishi N, Sugihara E, Kuninaka S, Miyamoto T, Morioka H, Nakayama R, Kobayashi E, Toyama Y, Mabuchi Y, Matsuzaki Y, Yamaguchi R, Miyano S, Saya H: Twist2 functions as a tumor suppressor in murine osteosarcoma cells. Cancer Sci 2013, 104:880-888.

20. Casas E, Kim J, Bendesky A, Ohno-Machado L, Wolfe CJ, Yang J: Snail2 is an essential mediator of Twist1-induced epithelial mesenchymal transition and metastasis. Cancer Res 2011, 71:245-254.

21. Gonzalez DM, Medici D: Signaling mechanisms of the epithelial-mesenchymal transition. Sci Signal 2014, 7:re8. Review.

22. Tirino V, Camerlingo R, Bifulco K, Irollo E, Montella R, Paino F, Sessa G, Carriero MV, Normanno N, Rocco G, Pirozzi G: TGF-beta1 exposure induces epithelial to mesenchymal transition both in CSCs and non-CSCs of the A549 cell line, leading to an increase of migration ability in the CD133+ A549 cell fraction. Cell Death Dis 2013, 4:e620

23. Eberlein C, Rooney C, Ross SJ, Farren M, Weir HM, Barry ST: E-Cadherin and EpCAM expression by NSCLC tumour cells associate with normal fibroblast activation through a pathway initiated by integrin alphavbeta6 and maintained through TGFbeta signalling. Oncogene 2014, Epub ahead of print.

24. Liu RY, Zeng Y, Lei Z, Wang L, Yang H, Liu Z, Zhao J, Zhang HT: JAK/STAT3 signaling is required for TGF-beta-induced epithelial-mesenchymal transition in lung cancer cells. Int J Oncol 2014, 44:1643-1651.

25. Jing Y, Han Z, Zhang S, Liu Y, Wei L: Epithelial-Mesenchymal Transition in tumor microenvironment. Cell Biosci 2011, 1:29.

26. Zheng $H$, Kang $Y$ : Multilayer control of the EMT master regulators. Oncogene 2014, 33:1755-1763.

27. Mateen S, Raina K, Agarwal C, Chan D, Agarwal R: Silibinin synergizes with histone deacetylase and DNA methyltransferase inhibitors in upregulating E-cadherin expression together with inhibition of migration and invasion of human non-small cell lung cancer cells. J Pharmacol Exp The 2013, 345:206-214.

28. Zhang X, Liu G, Kang Y, Dong Z, Qian Q, Ma X: N-cadherin expression is associated with acquisition of EMT phenotype and with enhanced invasion in erlotinib-resistant lung cancer cell lines. PLOS One 2013, 8:e57692.

29. Tischler V, Pfeifer M, Hausladen S, Schirmer U, Bonde AK, Kristiansen G, Sos ML, Weder W, Moch H, Altevogt P, Soltermann A: L1CAM protein expression is associated with poor prognosis in non-small cell lung cancer. Mol Cancer 2011, 10:127.

30. Gibbons DL, Lin W, Creighton CJ, Rizvi ZH, Gregory PA, Goodall GJ, Thilaganathan N, Du L, Zhang Y, Pertsemlidis A, Kurie JM: Contextual extracellular cues promote tumor cell EMT and metastasis by regulating miR-200 family expression. Genes Dev 2009, 23:2140-2151.

31. Guo F, Parker Kerrigan BC, Yang D, Hu L, Shmulevich I, Sood AK, Xue F, Zhang W: Post-transcriptional regulatory network of epithelial-tomesenchymal and mesenchymal-to-epithelial transitions. $J$ Hematol Oncol 2014, 7:19.

32. Bao B, Azmi AS, Ali S, Ahmad A, Li Y, Banerjee S, Kong D, Sarkar FH: The biological kinship of hypoxia with CSC and EMT and their relationship with deregulated expression of miRNAs and tumor aggressiveness. Biochim Biophys Acta 2012, 1826:272-296.

33. Espinoza I, Miele L: Deadly crosstalk: Notch signaling at the intersection of EMT and cancer stem cells. Cancer Lett 2013, 341:41-45

34. Matchett KB, Lappin TR: Concise reviews: cancer stem cells: from concept to cure. Stem Cells 2014, 32:2563-2570.

35. Lundin A, Driscoll B: Lung cancer stem cells: progress and prospects Cancer Lett 2013, 338:89-93.

36. Liu J, Xiao Z, Wong SK, Tin VP, Ho KY, Wang J, Sham MH, Wong MP: Lung cancer tumorigenicity and drug resistance are maintained through ALDH(hi)CD44(hi) tumor initiating cells. Oncotarget 2013, 4:1698-1711.

37. Kim CF, Jackson EL, Woolfenden AE, Lawrence S, Babar I, Vogel S, Crowley D, Bronson RT, Jacks T: Identification of bronchioalveolar stem cells in normal lung and lung cancer. Cell 2005, 121:823-835.

38. Templeton AK, Miyamoto S, Babu A, Munshi A, Ramesh R: Cancer stem cells:progress and challenges in lung cancer. Stem Cell Invest 2014, 1:9.

39. Paul MK, Bisht B, Darmawan DO, Chiou R, Ha VL, Wallace WD, Chon AT, Hegab AE, Grogan T, Elashoff DA, Alva-Ornelas JA, Gomperts BN: Dynamic changes in intracellular ROS levels regulate airway basal stem cell homeostasis through Nrf2-dependent Notch signaling. Cell Stem Cell 2014, 15:199-214.

40. Chiou SH, Wang ML, Chou YT, Chen CJ, Hong CF, Hsieh WJ, Chang HT, Chen YS, Lin TW, Hsu HS, Wu CW: Coexpression of Oct4 and Nanog enhances malignancy in lung adenocarcinoma by inducing cancer stem cell-like properties and epithelial-mesenchymal transdifferentiation. Cancer Res 2010, 70:10433-10444.

41. Capaccione KM, Pine SR: The Notch signaling pathway as a mediator of tumor survival. Carcinogenesis 2013, 34:1420-1430.

42. Andersson ER, Lendahl U: Therapeutic modulation of Notch signalling-are we there yet? Nat Rev Drug Discov 2014, 13:357-378.

43. Niessen K, Fu Y, Chang L, Hoodless PA, McFadden D, Karsan A: Slug is a direct Notch target required for initiation of cardiac cushion cellularization. J Cell Biol 2008, 182:315-325.

44. Gallahan D, Callahan R: The mouse mammary tumor associated gene INT3 is a unique member of the NOTCH gene family (NOTCH4). Oncogene 1997, 14:1883-1890.

45. Grabher $\mathrm{C}$, von Boehmer H, Look AT: Notch 1 activation in the molecular pathogenesis of T-cell acute lymphoblastic leukaemia. Nat Rev Cancer 2006, 6:347-359.

46. Zou J, Li P, Lu F, Liu N, Dai J, Ye J, Qu X, Sun X, Ma D, Park J, Ji C: Notch1 is required for hypoxia-induced proliferation, invasion and chemoresistance of T-cell acute lymphoblastic leukemia cells. J Hematol Oncol 2013, 6:3.

47. Li Z: CD133: a stem cell biomarker and beyond. Exp Hematol Oncol 2013, 2:17.

48. Wang Z, da Silva T, Jin K, Han X, Ranganathan P, Zhu X, Sanchez-Mejias A, Bai $F$, Li B, Fei DL, Weaver KL, Vasquez-Del Carpio R, Moscowitz AE, Koshenkov VP, Sanchez L, Sparling L, Pei XH, Franceschi D, Ribeiro A Robbins DJ, Livingstone AS, Capobianco AJ: Notch Signaling Drives Stemness and Tumorigenicity of Esophageal Adenocarcinoma. Cancer Res 2014, Epub ahead of print.

49. Rampias T, Vgenopoulou P, Avgeris M, Polyzos A, Stravodimos K, Valavanis C, Scorilas A, Klinakis A: A new tumor suppressor role for the Notch pathway in bladder cancer. Nat Med 2014, Epub ahead of print.

50. Allen TD, Rodriguez EM, Jones KD, Bishop JM: Activated Notch1 induces lung adenomas in mice and cooperates with Myc in the generation of lung adenocarcinoma. Cancer Res 2011, 71:6010-6018.

51. Licciulli S, Avila JL, Hanlon L, Troutman S, Cesaroni M, Kota S, Keith B, Simon MC, Puré E, Radtke F, Capobianco AJ, Kissil JL: Notch1 is required 
for Kras-induced lung adenocarcinoma and controls tumor cell survival via p53. Cancer Res 2013, 73:5974-5984.

52. Zheng Y, de la Cruz CC, Sayles LC, Alleyne-Chin C, Vaka D, Knaak TD, Bigos M, Xu Y, Hoang CD, Shrager JB, Fehling HJ, French D, Forrest W, Jiang Z, Carano RA, Barck KH, Jackson EL, Sweet-Cordero EA: A rare population of CD24(+)ITGB4(+)Notch(hi) cells drives tumor propagation in NSCLC and requires Notch3 for self-renewal. Cancer Cell 2013, 24:59-74.

53. Xu X, Huang L, Futtner C, Schwab B, Rampersad RR, Lu Y, Sporn TA, Hogan BL, Onaitis MW: The cell of origin and subtype of K-Ras-induced lung tumors are modified by Notch and Sox2. Genes Dev 2014, 28:1929-1939.

54. Eliasz S, Liang S, Chen Y, De Marco MA, Machek O, Skucha S, Miele L, Bocchetta M: Notch-1 stimulates survival of lung adenocarcinoma cells during hypoxia by activating the IGF-1R pathway. Oncogene 2010, 29:2488-2498

55. Chen Y, Li D, Liu H, Xu H, Zheng H, Qian F, Li W, Zhao C, Wang Z, Wang X: Notch-1 signaling facilitates survivin expression in human non-small cell lung cancer cells. Cancer Biol Ther 2011, 11:14-21.

56. Westhoff B, Colaluca IN, D'Ario G, Donzelli M, Tosoni D, Volorio S, Pelosi G, Spaggiari L, Mazzarol G, Viale G, Pece S, Di Fiore PP: Alterations of the Notch pathway in lung cancer. Proc Natl Acad Sci U S A 2009, 106:22293-22298.

57. Dang TP, Gazdar AF, Virmani AK, Sepetavec T, Hande KR, Minna JD, Roberts JR, Carbone DP: Chromosome 19 translocation, overexpression of Notch3, and human lung cancer. J Natl Cancer Inst 2000, 92:1355-1357.

58. Haruki N, Kawaquchi KS, Eichenberger S, Massion PP, Olson S, Gonzalez A, Carbone DP, Dang TP: Dominant-negative Notch3 receptor inhibits mitogen-activated protein kinase pathway and the growth of human lung cancers. Cancer Res 2005, 65:3555-3561.

59. Konishi J, Kawaguchi KS, Vo H, Haruki N, Gonzalez A, Carbone DP, Dang TP: Gamma-secretase inhibitor prevents Notch3 activation and reduces proliferation in human lung cancers. Cancer Res 2007, 67:8051-8057.

60. Konishi J, Yi F, Chen X, Vo H, Carbone DP, Dang TP: Notch3 cooperates with the EGFR pathway to modulate apoptosis through the induction of bim. Oncogene 2010, 29:589-596

61. Lin L, Mernaugh R, Yi F, Blum D, Carbone DP, Dang TP: Targeting specific regions of the Notch3 ligand-binding domain induces apoptosis and inhibits tumor growth in lung cancer. Cancer Res 2010, 70:632-638.

62. Donnem T, Andersen S, Al-Shibli K, Al-Saad S, Busund LT, Bremnes RM: Prognostic impact of Notch ligands and receptors in nonsmall cell lung cancer: coexpression of Notch-1 and vascular endothelial growth factor-A predicts poor survival. Cancer 2010, 116:5676-5685.

63. Ye YZ, Zhang ZH, Fan XY, Xu XL, Chen ML, Chang BW, Zhang YB: Notch3 overexpression associates with poor prognosis in human non-small-cell lung cancer. Med Oncol 2013, 30:595.

64. De Craene B, Berx G: Regulatory networks defining EMT during cancer initiation and progression. Nat Rev Cancer 2013, 13:97-110.

65. Timmerman LA, Grego-Bessa J, Raya A, Bertrán E, Pérez-Pomares JM, Díez J, Aranda S, Palomo S, McCormick F, Izpisúa-Belmonte JC, de la Pompa JL: Notch promotes epithelial-mesenchymal transition during cardiac development and oncogenic transformation. Genes Dev 2004, 18:99-115.

66. Chang AC, Garside VC, Fournier M, Smrz J, Vrljicak P, Umlandt P, Fuller $M$, Robertson G, Zhao Y, Tam A, Jones SJ, Marra MA, Hoodless PA, Karsan A: A Notch-dependent transcriptional hierarchy promotes mesenchymal transdifferentiation in the cardiac cushion. Dev Dyn 2014, 243:894-905.

67. Chen Y, Zheng S, Qi D, Zheng S, Guo J, Zhang S, Weng Z: Inhibition of Notch signaling by a gamma-secretase inhibitor attenuates hepatic fibrosis in rats. PLoS One 2012, 7:e46512.

68. Nyhan KC, Faherty N, Murray G, Cooey LB, Godson C, Crean JK, Brazil DP. Jagged/Notchsignalling is required for a subset of TGFbeta1 responses in human kidney epithelial cells. Biochim Biophys Acta 1803, 2010:1386-1395.

69. Wu K, Chen K, Wang C, Jiao X, Wang L, Zhou J, Wang J, Li Z, Addya S, Sorensen PH, Lisanti MP, Quong A, Ertel A, Pestell RG: Cell fate factor DACH1 represses YB-1-mediated oncogenic transcription and translation. Cancer Res 2014, 74:829-839.

70. Villarejo A, Cortés-Cabrera A, Molina-Ortíz P, Portillo F, Cano A: Differential role of Snail1 and Snail2 zinc fingers in E-cadherin repression and epithelial to mesenchymal transition. J Biol Chem 2014, 289:930-941.

71. Xie M, Zhang L, He CS, Xu F, Liu JL, Hu ZH, Zhao LP, Tian Y: Activation of Notch-1 enhances epithelial-mesenchymal transition in gefitinibacquired resistant lung cancer cells. J Cell Biochem 2012, 113:1501-1513.
72. Zheng $X$, Linke S, Dias JM, Zheng $X$, Gradin $K$, Wallis TP, Hamilton BR, Gustafsson M, Ruas JL, Wilkins S, Bilton RL, Brismar K, Whitelaw ML, Pereira T, Gorman JJ, Ericson J, Peet DJ, Lendahl U, Poellinger L: Interaction with factor inhibiting HIF-1 defines an additional mode of cross-coupling between the Notch and hypoxia signaling pathways. Proc Natl Acad Sci U S A 2008, 105:3368-3373.

73. Zhou L, Wang DS, Li QJ, Sun W, Zhang Y, Dou KF: The down-regulation of Notch1 inhibits the invasion and migration of hepatocellular carcinoma cells by inactivating the cyclooxygenase-2/Snail/E-cadherin pathway in vitro. Dig Dis Sci 2013, 58:1016-1025.

74. Capaccione KM, Hong X, Morgan KM, Liu W, Bishop JM, Liu L, Markert E, Deen $M$, Minerowicz C, Bertino JR, Allen T, Pine SR: Sox9 mediates Notch1-induced mesenchymal features in lung adenocarcinoma. Oncotarget 2014, 5:3636-3650.

75. Wang Z, Li Y, Kong D, Banerjee S, Ahmad A, Azmi AS, Ali S, Abbruzzese JL, Gallick GE, Sarkar FH: Acquisition of epithelial-mesenchymal transition phenotype of gemcitabine-resistant pancreatic cancer cells is linked with activation of the notch signaling pathway. Cancer Res 2009, 69:2400-2407.

76. Yang Y, Ahn YH, Chen Y, Tan X, Guo L, Gibbons DL, Ungewiss C, Peng DH, Liu X, Lin SH, Thilaganathan N, Wistuba II, Rodriguez-Canales J, McLendon G, Creighton CJ, Kurie JM: ZEB1 sensitizes lung adenocarcinoma to metastasis suppression by PI3K antagonism. J Clin Invest 2014, 124:2696-2708.

77. Argast GM, Krueger JS, Thomson S, Sujka-Kwok I, Carey K, Silva S, O'Connor M, Mercado P, Mulford IJ, Young GD, Sennello R, Wild R, Pachter JA, Kan JL, Haley J, Rosenfeld-Franklin M, Epstein DM: Inducible expression of TGF $\beta$, snail and Zeb1 recapitulates EMT in vitro and in vivo in a NSCLC model. Clin Exp Metastasis 2011, 28:593-614.

78. Spaderna S, Schmalhofer O, Wahlbuhl M, Dimmler A, Bauer K, Sultan A, Hlubek F, Jung A, Strand D, Eger A, Kirchner T, Behrens J, Brabletz T: The transcriptional repressor ZEB1 promotes metastasis and loss of cell polarity in cancer. Cancer Res 2008, 68:537-544.

79. Ren J, Chen Y, Song H, Chen L, Wang R: Inhibition of ZEB1 reverses EMT and chemoresistance in docetaxel-resistant human lung adenocarcinoma cell line. J Cell Biochem 2013, 114:1395-1403.

80. Merikallio H, Kaarteenaho R, Pääkkö P, Lehtonen S, Hirvikoski P, Mäkitaro R, Soini $Y$ : Zeb1 and twist are more commonly expressed in metastatic than primary lung tumours and show inverse associations with claudins. J Clin Pathol 2011, 64:136-140.

81. Yang $Y$, Ahn $Y H$, Gibbons DL, Zang Y, Lin W, Thilaganathan N, Alvarez CA, Moreira DC, Creighton CJ, Gregory PA, Goodall GJ, Kurie JM: The Notch ligand Jagged2 promotes lung adenocarcinoma metastasis through a miR-200-dependent pathway in mice. J Clin Invest 2011, 121:1373-1385.

82. Zavadil J, Böttinger EP: TGF-beta and epithelial-to-mesenchymal transitions. Oncogene 2005, 24:5764-5774.

83. Lin LC, Hsu SL, Wu CL, Hsueh CM: TGF $\beta$ can stimulate the p38/b-cetanin/ PPARy signaling pathway to promote the EMT, invasion and migration of non-small cell lung cancer (H460 cells). Clin Exp Metastasis 2014, Epub ahead of print.

84. Zhang HJ, Wang HY, Zhang HT, Su JM, Zhu J, Wang HB, Zhou WY, Zhang H, Zhao MC, Zhang L, Chen XF: Transforming growth factor- $\beta 1$ promotes lung adenocarcinoma invasion and metastasis by epithelial-to-mesenchymal transition. Mol Cell Biochem 2011, 355:309-414.

85. Zavadil J, Cermak L, Soto-Nieves N, Böttinger EP: Integration of TGF-beta/ Smad and Jagged1/Notch signalling in epithelial-to-mesenchymal transition. EMBO J 2004, 23:1155-1165.

86. Matsuno Y, Coelho AL, Jarai G, Westwick J, Hogaboam CM: Notch signaling mediates TGF-beta1-induced epithelial-mesenchymal transition through the induction of Snai1. Int J Biochem Cell Biol 2012, 44:776-789.

87. Tsai TH, Sun MH, Ho TC, Ma HI, Liu MY, Tsao YP: Notch prevents transforming growth factor-beta-assisted epithelial-mesenchymal transition in cultured limbal progenitor cells through the induction of smad7. Mol Vis 2014, 20:522-534.

88. Han L, Diehl A, Nguyen N, Korangath P, Teo W, Cho S, Kominsky S, Huso D, Feigenbaum L, Rein A, Argani P, Landberg G, Gessler M, Sukumar S: The Notch pathway inhibits TGF- $\beta$ signaling in breast cancer through HEYL-mediated crosstalk. Cancer Res 2014, Epub ahead of print.

89. Casimiro MC, Velasco-Velázquez M, Aguirre-Alvarado C, Pestell RG: Overview of cyclins D1 function in cancer and the CDK inhibitor landscape: past and present. Expert Opin Investig Drugs 2014, 23:295-304.

90. Zimonjic DB, Chan LN, Tripathi V, Lu J, Kwon O, Popescu NC, Lowy DR, Tamanoi F: In vitro and in vivo effects of geranylgeranyltransferase I 
inhibitor P61A6 on non-small cell lung cancer cells. BMC Cancer 2013, 13:198.

91. Wang Y, Dong QZ, Fu L, Stoecker M, Wang E, Wang EH: Overexpression of CRKL correlates with poor prognosis and cell proliferation in non-small cell lung cancer. Mol Carcinog 2013, 52:890-899.

92. Jiao J, Huang L, Ye F, Shi M, Cheng X, Wang X, Hu D, Xie X, Lu W: Cyclin D1 affects epithelial-mesenchymal transition in epithelial ovarian cancer stem cell-like cells. Onco Targets Ther 2013, 6:667-677.

93. Koay MH, Crook M, Stewart CJ: Cyclin D1, E-cadherin and beta-catenin expression in FIGO Stage IA cervical squamous carcinoma: diagnostic value and evidence for epithelial-mesenchymal transition. Histopathology 2012, 61:1125-1133.

94. Mejlvang J, Kriajevska M, Vandewalle C, Chernova T, Sayan AE, Berx G, Mellon JK, Tulchinsky E: Direct repression of cyclin D1 by SIP1 attenuates cell cycle progression in cells undergoing an epithelial mesenchymal transition. Mol Biol Cell 2007, 18:4615-4624.

95. Alqudah MA, Agarwal S, Al-Keilani MS, Sibenaller ZA, Ryken TC, Assem M: NOTCH3 is a prognostic factor that promotes glioma cell proliferation, migration and invasion via activation of CCND1 and EGFR. PLoS One 2013, 8:e77299.

96. Das D, Lanner F, Main H, Andersson ER, Bergmann O, Sahlgren C, Heldring N Hermanson O, Hansson EM, Lendahl U: Notch induces cyclin-D1-dependent proliferation during a specific temporal window of neural differentiation in ES cells. Dev Biol 2010, 348:153-166.

97. Maraver A, Fernandez-Marcos PJ, Herranz D, Cañamero M, Muñoz-Martin M, Gómez-López G, Mulero F, Megías D, Sanchez-Carbayo M, Shen J, Sanchez-Cespedes M, Palomero T, Ferrando A, Serrano M: Therapeutic effect of $\gamma$-secretase inhibition in KrasG12V-driven non-small cell lung carcinoma by derepression of DUSP1 and inhibition of ERK. Cancer Cell 2012, 22:222-234.

98. Takebe N, Nguyen D, Yang SX: Targeting notch signaling pathway in cancer: clinical development advances and challenges. Pharmacol Ther 2014, 141:140-149.

99. Tolcher AW, Messersmith WA, Mikulski SM, Papadopoulos KP, Kwak EL, Gibbon DG, Patnaik A, Falchook GS, Dasari A, Shapiro Gl, Boylan JF, Xu ZX, Wang K, Koehler A, Song J, Middleton SA, Deutsch J, Demario M, Kurzrock R, Wheler JJ: Phase I study of RO4929097, a gamma secretaseinhibitor of Notch signaling, in patients with refractory metastatic or locally advanced solid tumors. J Clin Oncol 2012, 30:2348-2353.

100. Lee SM, Moon J, Redman BG, Chidiac T, Flaherty LE, Zha Y, Othus M, Ribas A, Sondak VK, Gajewski TF, Margolin KA: Phase 2 study of RO4929097, a gamma-secretaseinhibitor, in metastatic melanoma: SWOG 0933. Cancer 2014, Epub ahead of print.

101. Strosberg JR, Yeatman T, Weber J, Coppola D, Schell MJ, Han G, Almhanna K, Kim R, Valone T, Jump H, Sullivan D: A phase II study of R04929097 in metastatic colorectal cancer. Eur J Cancer 2012, 48:997-1003.

102. De Jesus-Acosta A, Laheru D, Maitra A, Arcaroli J, Rudek MA, Dasari A, Blatchford PJ, Quackenbush K, Messersmith W: A phase II study of the gamma secretaseinhibitor RO4929097 in patients with previously treated metastatic pancreatic adenocarcinoma. Invest New Drugs 2014, 32:739-745

103. Messersmith WA, Shapiro GI, Cleary JM, Jimeno A, Dasari A, Huang B, Shaik MN, Cesari R, Zheng X, Reynolds JM, English PA, McLachlan KR, Kern KA, LoRusso PM: A Phase I, Dose-finding Study in Patients With Advanced Solid Malignancies of the Oral Gamma-Secretaselnhibitor PF-03084014. Clin Cancer Res 2014, Epub ahead of print.

104. Stoeck A, Lejnine S, Truong A, Pan L, Wang H, Zang C, Yuan J, Ware C, MacLean J, Garrett-Engele PW, Kluk M, Laskey J, Haines BB, Moskaluk C, Zawel L, Fawell S, Gilliland G, Zhang T, Kremer BE, Knoechel B, Bernstein BE, Pear WS, Liu XS, Aster JC, Sathyanarayanan S: Discovery of Biomarkers Predictive of GSI Response in Triple-Negative Breast Cancer and Adenoid Cystic Carcinoma. Cancer Discov 2014, Epub ahead of print

105. Mizuma M, Rasheed ZA, Yabuuchi S, Omura N, Campbell NR, de Wilde RF, De Oliveira E, Zhang Q, Puig O, Matsui W, Hidalgo M, Maitra A, Rajeshkumar NV: The gamma secretase inhibitor MRK-003 attenuates pancreatic cancer growth in preclinical models. Mol Cancer Ther 2012, 11:1999-2009.

106. Ramakrishnan V, Ansell S, Haug J, Grote D, Kimlinger T, Stenson M, Timm M, Wellik L, Halling T, Rajkumar SV, Kumar S: MRK003, a $\gamma$-secretaseinhibitor exhibits promising in vitro pre-clinical activity in multiple myeloma and non-Hodgkin's lymphoma. Leukemia 2012, 26:340-348.
107. Schott AF, Landis MD, Dontu G, Griffith KA, Layman RM, Krop I, Paskett LA, Wong H, Dobrolecki LE, Lewis MT, Froehlich AM, Paranilam J, Hayes DF, Wicha MS, Chang JC: Preclinical and clinical studies of gamma secretase inhibitors with docetaxel on human breast tumors. Clin Cancer Res 2013 19:1512-1524

108. Krop I, Demuth T, Guthrie T, Wen PY, Mason WP, Chinnaiyan P, Butowski N, Groves MD, Kesari S, Freedman SJ, Blackman S, Watters J, Loboda A, Podtelezhnikov A, Lunceford J, Chen C, Giannotti M, Hing J, Beckman R, Lorusso P: Phase I pharmacologic and pharmacodynamic study of the gamma secretase (Notch) inhibitor MK-0752 in adult patients with advanced solid tumors. J Clin Oncol 2012, 30:2307-2313.

109. Liu YP, Yang CJ, Huang MS, Yeh CT, Wu AT, Lee YC, Lai TC, Lee CH, Hsiao YW, Lu J, Shen CN, Lu PJ, Hsiao M: Cisplatin selects for multidrug-resistant CD133 + cells in lung adenocarcinoma by activating Notch signaling. Cancer Res 2013, 73:406-416.

110. Jiang $L Y$, Zhang $X L$, Du P, Zheng JH: $\gamma$-Secretaselnhibitor, DAPT Inhibits Self-renewal and Stemness Maintenance of Ovarian Cancer Stem-like Cells In Vitro. Chin J Cancer Res 2011, 23:140-146.

111. Arasada RR, Amann JM, Rahman MA, Huppert SS, Carbone DP: EGFR Blockade Enriches for Lung Cancer Stem-like Cells through Notch3-Dependent Signaling. Cancer Res 2014, Epub ahead of print.

112. Mizugaki H, Sakakibara-Konishi J, Ikezawa Y, Kikuchi J, Kikuchi E, Oizumi S, Dang TP, Nishimura M: $\gamma$-Secretase inhibitor enhances antitumour effect of radiation in Notch-expressing lung cancer. Br J Cancer 2012, 106:1953-1959.

113. Sureban SM, May R, Mondalek FG, Ou D, Ponnurangam S, Pantazis P, Anant S, Ramanujam RP, Houchen CW: Nanoparticle-based delivery of siDCAMKL-1 increases microRNA-144 and inhibits colorectal cancer tumor growth via a Notch-1 dependent mechanism. J Nanobiotechnology 2011, 9:40.

114. Wu Y, Cain-Hom C, Choy L, Hagenbeek TJ, de Leon GP, Chen Y, Finkle D, Venook R, Wu X, Ridgway J, Schahin-Reed D, Dow GJ, Shelton A, Stawicki S, Watts RJ, Zhang J, Choy R, Howard P, Kadyk L, Yan M, Zha J, Callahan CA, Hymowitz SG, Siebel CW: Therapeuticantibodytargeting of individualNotch receptors. Nature 2010, 464:1052-1057.

115. Li Y, Burns JA, Cheney CA, Zhang N, Vitelli S, Wang F, Bett A, Chastain M, Audoly LP, Zhang ZQ: Distinct expression profiles of Notch-1 protein in human solid tumors: Implications for development of targeted therapeutic monoclonal antibodies. Biologics 2010, 4:163-171.

116. Filipović A, Lombardo Y, Fronato M, Abrahams J, Aboagye E, Nguyen QD, d'Aqua BB, Ridley A, Green A, Rahka E, Ellis I, Recchi C, Przulj N, Sarajlić A, Alattia JR, Fraering P, Deonarain M, Coombes RC: Anti-nicastrin monoclonal antibodies elicit pleiotropic anti-tumour pharmacological effects in invasive breast cancer cells. Breast Cancer Res Treat 2014, Epub ahead of print

117. Ahmad A, Sakr WA, Rahman KM: Novel targets for detection of cancer and their modulation by chemopreventive natural compounds. Front Biosci (Elite Ed) 2012, 4:410-425.

118. Li Y, Zhang J, Ma D, Zhang L, Si M, Yin H, Li J: Curcumin inhibits proliferation and invasion of osteosarcoma cells through inactivation of Notch-1 signaling. FEBS J 2012, 279:2247-2259.

doi:10.1186/s13045-014-0087-z

Cite this article as: Yuan et al:: Notch signaling and EMT in non-small cell lung cancer: biological significance and therapeutic application. Journal of Hematology \& Oncology 2014 7:87.

\section{Submit your next manuscript to BioMed Central and take full advantage of:}

- Convenient online submission

- Thorough peer review

- No space constraints or color figure charges

- Immediate publication on acceptance

- Inclusion in PubMed, CAS, Scopus and Google Scholar

- Research which is freely available for redistribution 